\title{
Effectiveness of Health Education Programme on Knowledge regarding Mosquito Control Measures among Adults of Urban Area, Puducherry
}

\author{
*Ms. Jibi Susan, **Dr. Rebecca Samson \& ***Mrs. Anusuya.D
}

\section{Abstract:}

Objectives:To assess the socio-demographic characteristics of the study adults, To assess the effectiveness of planned teaching programme on mosquito control measures to find the association between posttest knowledge level with their selected socio-demographic variables. Methods: A Quasi experimental study design was used for this study. A total 30 adults between the age group of 21-60 years. Data collection was done by door to door survey method using pretested structured interview schedule before and after health education program at Muthialpet, Puducherry. The tool contained demographic profile of participants, knowledge about mosquito control measures. Pre-test was conducted using structured interview schedule followed by the teaching program was administered by using flash cards, charts and discussion with them. After a week (7-days) post-test data was collected. Results were analyzed statistically using percentage, proportions and Chi-square test was applied. Results: The results revealed that, in pre-test most of them $96.7 \%$ had inadequate knowledge and 3.3\% had moderately adequate knowledge. During posttest 40\% had adequate knowledge, 50\% had moderate knowledge and 10\% had inadequate knowledge. Highly significant difference was found between pre-test and post-test score $(p<0.01)$. Conclusion: The study concluded that, Planned teaching programme regarding mosquito control measures has been effective in gaining knowledge among adults

Keywords: Health Education Programme, Mosquito Control Measures and Adults.

\section{INTRODUCTION}

Mosquitoes are often annoying pests and are carriers of other organisms that cause diseases. Mosquito borne diseases are the major health problem all over the world and India causing morbidity and mortality of all disease-transmitting insects, the mosquito is the greatest menace, spreading malaria, dengue, lymphatic filariasis and Japanese encephalitis and yellow fever, which together are responsible for several million deaths and hundreds of millions of cases every year. ${ }^{2}$ Vector-borne diseases account for $17 \%$ of the estimated global burden of all infectious diseases. The world's fastest growing vector-borne disease is dengue, with a 30 -fold increase in disease incidence over the last 50 years. About 2500 million people worldwide at risk of Dengue and 20 million cases a year in more than 100 countries $^{4}$

India is struggling to cope with outbreaks of mosquito borne diseases that kills and infects the people. Control of mosquitoes is important in the present day with rising number of 
mosquito borne diseases, only possible through community participation in turn depends on people's knowledge towards the disease and its prevention. ${ }^{3}$

So, this study was undertaken with the objective to study the knowledge of adults before and after implementation of Health education programme regarding mosquito control measures and associate knowledge with selected demographic variables towards designing community-based interventions.

\section{STATEMENT OF THE PROBLEM:}

A Study to Assess the Effectiveness Of Health Education Programme On Knowledge Mosquito Control Measures Among Adults Of Urban Area, Puducherry."

\section{OBJECTIVES:}

1. To assess the socio-demographic characteristics of the study adults.

2. To assess the effectiveness of planned teaching programme on mosquito control measuresamong urbanadults.

3. To find the association between post test knowledge level with their selected socio-demographic variables.

\section{METHODS}

A Quantitative approach and Quasi experimental study design was used for this study. Total 30 adults between the age group of 21-60 years, who were willing to participate in the study, were included. Data collection was done by door to door survey method using pretested structured interview schedule before and after health education program at Muthialpet, Puducherry. Confidentiality was assured to all participants and informed consent was taken from them. Pre-test was conducted using structured interview schedule followed by teaching program was administered by using flash cards, charts and discussion with them.

After a week (7-days) post-test data was collected. Results were analyzed statistically using percentage, proportions and Chi-square test was applied

\section{RESULTS:}

\section{Distribution of Knowledge Level Regarding Mosquito Control Measures among Adults before and after Planned Teaching Programme.}

The results reveal that, 29(96.7) adults had inadequate knowledge and $1(3.3 \%)$ had moderately adequate knowledge regarding mosquito control measures in pre-test. In post test adults $10 \%$ had inadequate knowledge, 50\% had moderately adequate knowledge and $40 \%$ gained adequate knowledge in post-test.

Table-1: Effectiveness of Planned Teaching Programme Regarding Mosquito Control Measures among Adults $\quad n=30$

\begin{tabular}{|c|c|c|c|c|}
\hline \multirow{2}{*}{ Knowledge } & \multicolumn{2}{|c|}{ Difference } & \multirow{2}{*}{ 't'value } & \multirow{2}{*}{ 'p'value } \\
\cline { 2 - 3 } & Mean & S.D & & \\
\cline { 1 - 1 } Pre-test & 9.2 & 2.7 & 13.4 & $<0.001$ \\
\hline Post-test & & & & \\
\hline
\end{tabular}

*paired t test was used; highly Statistically Significant at 0.01 level 


\section{CONCLUSION}

The results reveal that, 29(96.7) adults had inadequate knowledge and $1(3.3 \%)$ had moderately adequate knowledge regarding mosquito control measures in pre-test. In post test adults $10 \%$ had inadequate knowledge, 50\% had moderately adequate knowledge and 40\% gained adequate knowledge in post-test. The difference in the level of knowledge regarding mosquito control measures among adults before and after health teaching programme was statistically highly significant and the paired ' $t$ ' test value was 13.4 at $\mathrm{p}<0.001$ and there was no significant association between knowledge level regarding mosquito control measures among adults with socio demographic variables. The results showed that there was a highly significant difference between pre and post test knowledge
( $\mathrm{p}$ value <0.001) Which reveals health teaching programme was effective towards control of mosquito and helps in bringing positive behavioral change to prevent vector borne diseases in the community.

\section{REFERENCES}

1. Xing Ping Hu2012, Mosquitos in and around home, Alabama Cooperative Extension System.

2. WHO. World health report 1996 [Internet]. Geneva: WHO; 2017.

3. http://www.who.int/whr/1996/media _centre/executive_summary1/en/inde $\mathrm{x} 10 . \mathrm{html}$

4. James M. Hughes, 1995, Emerging Infectious Diseases: Meeting the Challenge, Emerging Infectious Diseases, Vol 1: 3

\section{$\mathbf{P}_{\text {umonos }}$}

\section{CAUSES OF NEW ONSET ATRIAL FIBRILLATION

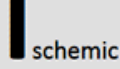

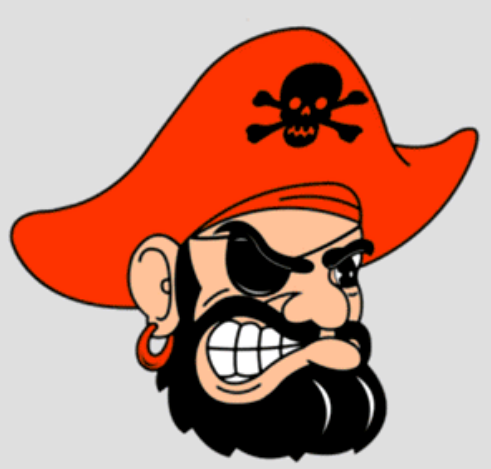
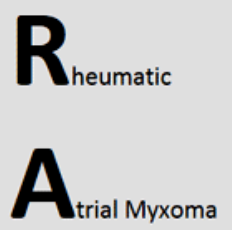

\section{Acute Management of New Onset A-Fib:}

- Hemodynamically Stable: Goal HR $<100$

Diltiazem $15 \mathrm{mg}$ IV then continuous drip titration

- Hemodynamically Unstable:

Electrical Cardioversion Sedate then shock (100J, 200J, 300J until sinus)
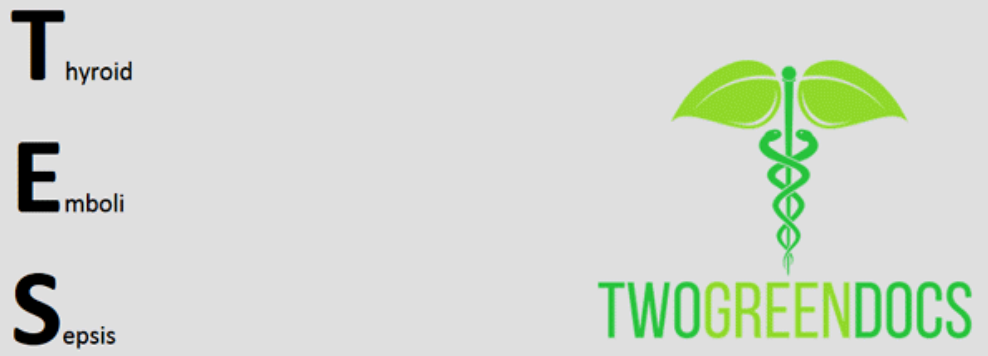